\title{
Ablepharon macrostomia syndrome in a Thai patient: case report and literature review
}

\author{
Phawin Kor-anantakul', Kanya Suphapeetiporn ${ }^{2,3}$, Somchit Jaruratanasirikul ${ }^{1, *}$
}

\begin{abstract}
Ablepharon macrostomia syndrome (AMS) is a rare congenital disorder. To our knowledge, only 20 cases have been reported to date, and all in patients from Western countries. We report a case of AMS in a Thai patient, who presented at age 3 months with severe ectropion of both upper and lower eyelids, alopecia totalis, no palpable clitoris, and hypoplasia of both labia minora and labia majora. Trio whole exome sequencing analysis was performed, which revealed a heterozygous missense c.223G $>$ A (p.Glu75Lys) variation in TWIST2. To our knowledge, this is the first reported case of AMS in a patient from Thailand and the first reported case of AMS in Asia.
\end{abstract}

Keywords: ablepharon macrostomia syndrome; Barber Say syndrome; lagophthalmos; TWIST2; whole exome sequencing

In 1977, McCarthy and West described 2 boys with similar clinical features including absent eyelids, alopecia totalis (eyebrows, eyelashes, and hair), large mouth, malformed ears, expressionless facies, and ambiguous genitalia with cryptorchidism, and they named this congenital disorder "ablepharon macrostomia syndrome" (AMS) [1]. AMS is a rare autosomal dominant congenital disorder (AMS; Online Mendelian Inheritance in Man (OMIM) 200110) [2]. To our knowledge, only 20 cases have been reported to date, and all in patients from Western countries [2-21]. Of these, 10 cases were examined by molecular studies, which confirmed a TWIST2 variation [20].

\section{Case report}

A 3-month-old girl was referred to Songklanagarind Hospital, a 1,000-bed teaching hospital of Prince of Songkla University in Southern Thailand, for evaluation of multiple congenital anomalies. She was born at a provincial hospital, a third child to parents (46-year-old mother and a 44-year-old father) who were nonconsanguineous. She was delivered by cesarean section at 35 weeks' gestation due to fetal distress. Her birth weight was 2,430 g (45th percentile), length $46 \mathrm{~cm}$ (52nd percentile), and head circumference $33 \mathrm{~cm}$ (78th percentile) [22].

Postnatally, it was observed that she had dysmorphic features, which are a severe abnormality of the eyelids that needed eye lubricants (Figure 1). She had no family history of genetic or ocular diseases. On her first day of life, she was intubated as she had respiratory distress. After extubation at 4 days of life, she fully recovered, received formula feeding, and gained some weight. She was discharged home at 20 days of age at a weight of 2,500 $\mathrm{g}$.

At 3 months of age, she was referred to our institution. Physical examination found weight $4.0 \mathrm{~kg}$, length $54 \mathrm{~cm}$,

\footnotetext{
*Correspondence to: Somchit Jaruratanasirikul, Department of Pediatrics, Faculty of Medicine, Prince of Songkla University, Hat Yai, Songkhla 90110, Thailand, e-mail: somchit.j@psu.ac.th

${ }^{1}$ Department of Pediatrics, Faculty of Medicine, Prince of Songkla University, Hat Yai, Songkhla 90110, Thailand

${ }^{2}$ Department of Pediatrics, Faculty of Medicine, Center of Excellence for Medical Genomics, Chulalongkorn University, Bangkok 10330, Thailand

${ }^{3}$ Excellence Center for Genomics and Precision Medicine, King Chulalongkorn Memorial Hospital, Thai Red Cross Society, Bangkok 10330, Thailand
} 


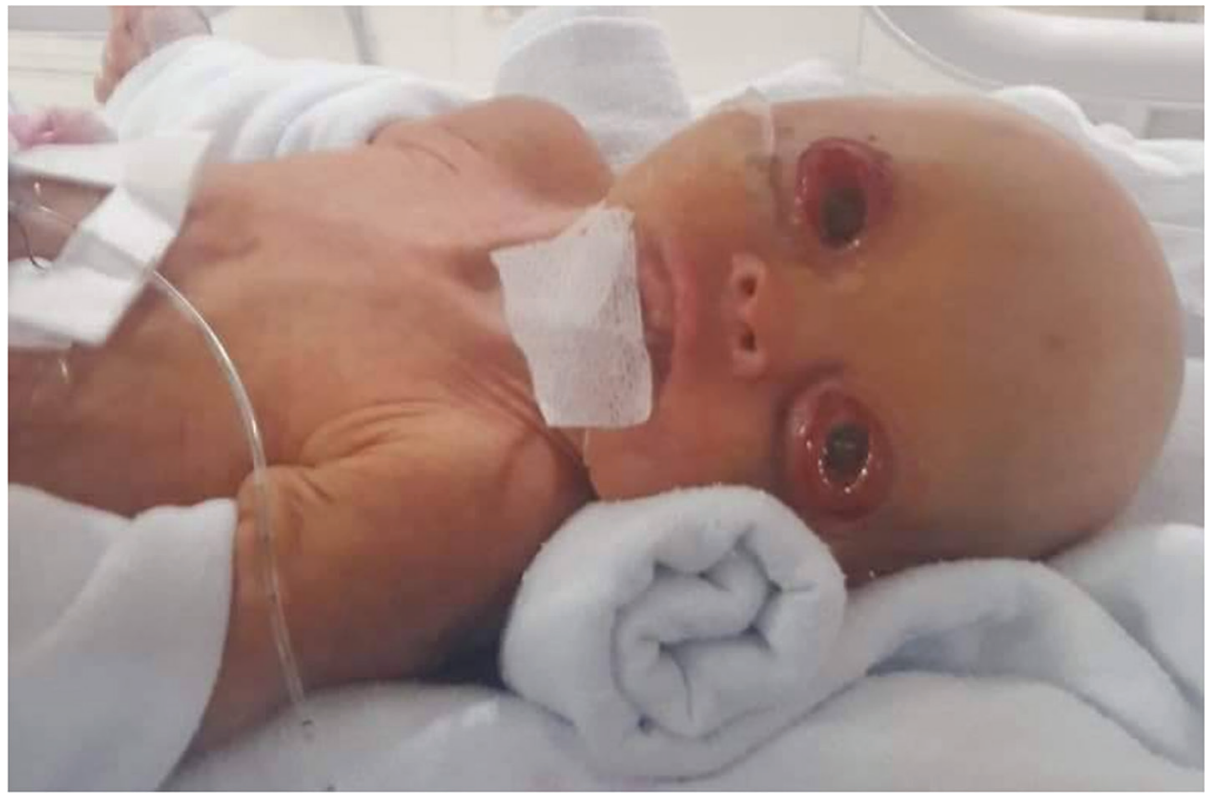

Figure 1. The patient at 1 week old, note the severe ectropion, macrostomia, and alopecia totalis (with consent from the mother of the patient for publication).

and head circumference $36 \mathrm{~cm}$, all of which were between the 3rd and 10th percentiles for unadjusted normal growth of Thai girls. She had severe ectropion of both upper and lower eyelids, ablepharon, alopecia totalis (hair, eyebrows, and eyelashes), hypertelorism, a flat nasal bridge, thick and flared alae nasi, flat malar eminences, a wide mouth, enlarged cheek pads, micrognathia, small, low-set ears, and an abnormally formed left ear. Her hands and feet were normal. Her skin was thin, redundant, and wrinkled with excessive creases in all extremities. An examination of her genitalia found no palpable clitoris, hypoplasia of both labia minora and labia majora, and vaginal stenosis. Her anus was located anteriorly (Figure 2). Chromosome analysis revealed 46, XX karyotype.

The main problem for our patient was the severe ectropion that required treatment with eye lubricants and eye shields, for which she was followed up every 6-8 weeks by an ophthalmologist. Physical growth and mental milestones were assessed every 3-4 months and were within normal ranges. She continued to grow well with her weight, length, and head circumference increasing according to 3rd-10th percentiles for normal Thai girls. Developmental milestones, as assessed at every follow-up visit by a Denver II test, were average for her age in all domains. At age 1 year, she weighed $8.2 \mathrm{~kg}$ with a body length of $71 \mathrm{~cm}$ and head circumference $44 \mathrm{~cm}$. To treat her eye problems, full-thickness skin grafting operation was performed at 1 year and 2 months old and permanent tarsorrhaphy at 1 year and 6 months old, and at that time she weighed $9.4 \mathrm{~kg}$ with a body length of $77 \mathrm{~cm}$ and head circumference $46 \mathrm{~cm}$ (Figure 3). She had no erupted teeth at age 2 years.

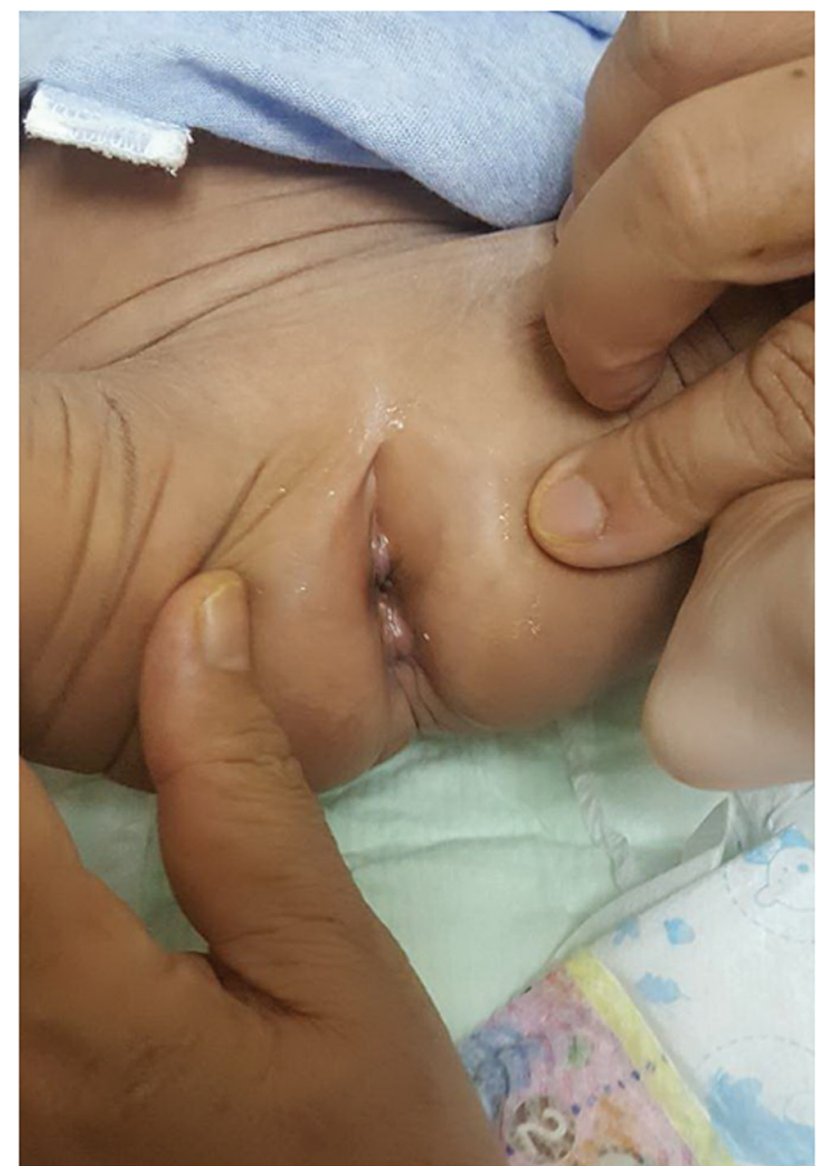

Figure 2. Genital examination, note absent clitoris, and the anteriorly located anus (with consent from the mother of the patient for publication). 


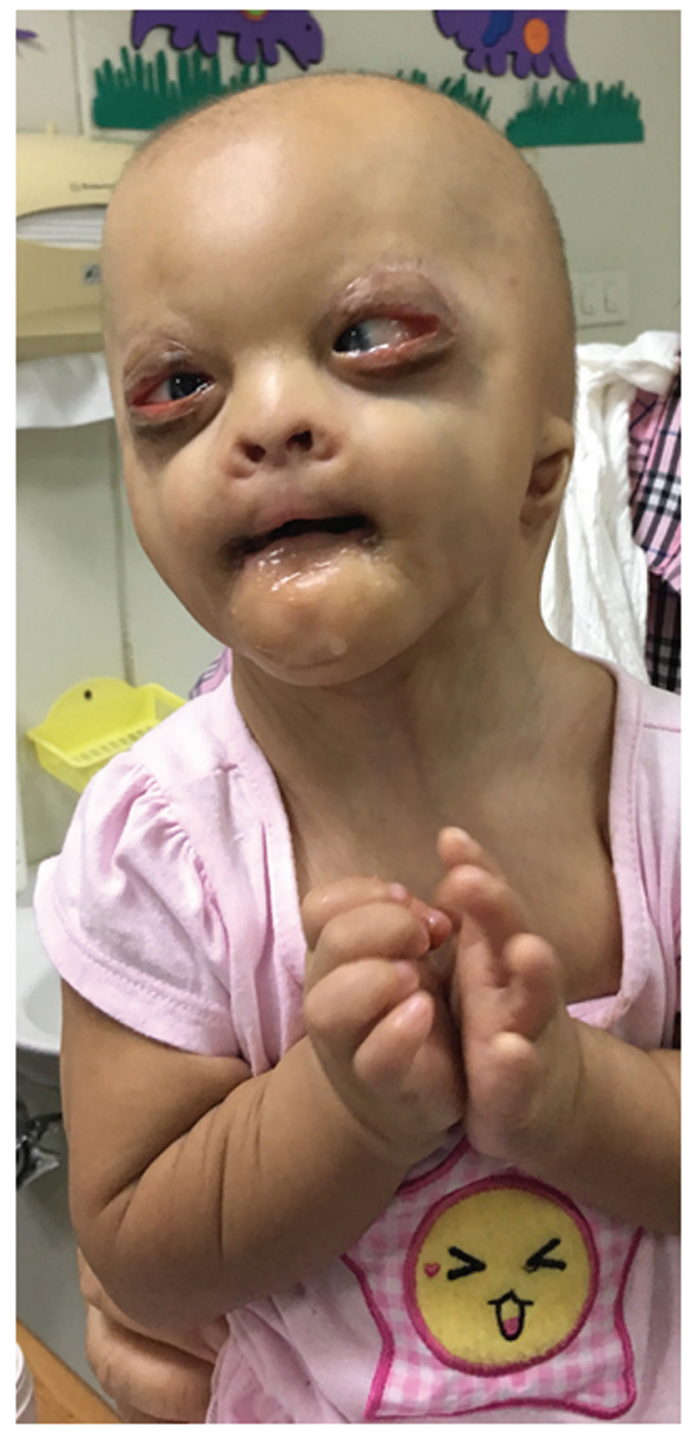

Figure 3. The patient at 1 year and 6 months old, note the improvement of the eyelids following skin graft (with consent from the mother of the patient for publication).

We decided to send a blood sample for whole exome sequencing (WES) at 9 months of age because the anomalies seemed to be severe and a comprehensive gene variation study was required to give us more insight into her underlying problems and to counsel her parents regarding their child's long-term prognosis. After written informed consent was obtained from her parents, $3 \mathrm{~mL}$ of peripheral blood was obtained and genomic DNA was extracted from leukocytes using a Puregene blood kit (Qiagen). A DNA sample was prepared according to Illumina sequencing. In the exome capture step, the sequencing libraries were enriched using SureSelect Human All Exon V5 kits. The captured libraries were sequenced using an Illumina HiSeq 4000 Sequencer. Trio WES analysis was performed at the Excellence Center for Medical Genetics, King Chulalongkorn Memorial Hospital, Bangkok. All single-nucleotide variants [SNVs; formerly known as single-nucleotide polymorphisms (SNPs)] and indels were filtered using the following criteria: (1) located in exons or flanking introns of the listed genes, (2) not synonymous, (3) rare with 1000 $\mathrm{G}$ minor allele frequency of $<1 \%,(4)<10$ in the Exome Aggregation Consortium (ExAC) database, (5) $<3$ alleles in 1,084 Thai exome controls, (6) (if the variant was a missense) predicted to be damaging by SIFT and Polyphen, and (7) related to the phenotype of the patient.

A heterozygous missense c.223G $>$ A (p.Glu75Lys) variation in TWIST2 was identified in the patient, but not in the parents by the trio-WES analysis. (chr2:239757079 G/A, p.Glu75Lys (E75K), rs796065049, [G/A]AGCGCCAGCGCACCCAGTCG, forward strand).

The mother of the patient consented to publication of this case report including all clinical photographs. The Institutional Review Board of the Faculty of Medicine, Prince of Songkla University approved the publication of this case (approval No. REC.62-056-1-1).

\section{Discussion}

Our patient had the clinical features of severe eye abnormalities (ectropion, absent eyelids), skin defects consistent with ectodermal dysplasia (thin, redundant and wrinkled skin, alopecia totalis, including absent eyebrows and eyelashes), and genital abnormalities (absent clitoris and hypoplasia of labia minora and labia majora). Although these clinical features, especially ectropion, are very specific to AMS, and these findings together are extremely rare, making the disease very difficult to simply and confidently diagnose by general pediatricians and ophthalmologists, even in a major teaching hospital such as ours. Therefore, we used WES to confirm the diagnosis of this rare syndrome. Although WES was used to confirm our diagnosis, this disease can also be confirmed by the much simpler Sanger sequencing, and a physician who has had previous experience with this method can use it to confirm a suspected case.

There are two other clinical syndromes, Barber-Say syndrome (BSS) and Setleis syndrome (FFDD3), focal facial dermal dysplasia type 3 , in which those affected will have clinical characteristics similar to AMS, such as the congenital skin, eye, and genital anomalies, mentioned above $[1,21,23,24]$. However, there are some distinct clinical features that can be used to differentiate between the 3 syndromes, such as the hypertrichosis in BSS, or distichiasis of the upper eyelashes and bitemporal scarring in FFDD3 (Table 1). When WES became available, the causative gene defects of 
AMS and BSS were identified as being on the same gene, TWIST2, but with different missense variants or at different alleles; the p.Glu75Lys missense variant for AMS, a missense variant of p.Glu75Gln or p.Glu75Ala for BSS, and a duplication variant of p.Gln77_Arg78dup [19]. Both AMS and BSS have autosomal dominant inheritance. TWIST2 variations have also been identified in some FFDD3 patients as homozygous missense, nonsense, or frameshift variants of p.Leu109Pro, p.Gln119Ter, p.Gln65Ter, p.Arg31Glyfs*71, or p.Ser57Alafs $* 45[25,26]$. In our patient, a WES of the missense variant on TWIST2, p.Glu75Lys, confirmed the diagnosis of AMS.

Table 1. Clinical characteristics of the patient with ablepharon macrostomia syndrome compared with patients other syndromes having a TWIST2 variation

\begin{tabular}{|c|c|c|c|c|}
\hline Clinical characteristic & Present case & $\begin{array}{c}\text { AMSt } \\
(\%)\end{array}$ & $\begin{array}{c}\text { BSS } \neq \\
(\%)\end{array}$ & $\begin{array}{c}\text { FFDD3§ } \\
(\%)\end{array}$ \\
\hline TWIST2 mutation & p.Glu75Lys & p.Glu75Lys & $\begin{array}{l}\text { p.Glu75GIn, p.Glu75Ala, } \\
\text { p.Gln77_Arg78dup }\end{array}$ & $\begin{array}{l}\text { p.Leu109Pro, p.GIn119Ter, p.Gln65Ter, } \\
\text { p.Arg31Glyfs*71, p.Ser57Alafs*45 }\end{array}$ \\
\hline \multicolumn{5}{|l|}{ Ophthalmic morphology } \\
\hline Absent eyelids & + & 75 & 6 & - \\
\hline Ectropion & + & 94 & 81 & - \\
\hline Entropion & - & 6 & - & $-\dagger+$ \\
\hline \multicolumn{5}{|l|}{ Facial morphology } \\
\hline Bitemporal narrowing & + & 56 & 50 & 100 \\
\hline Excessive creases & + & 81 & 81 & 89 \\
\hline Macrostomia & + & 81 & 100 & 33 \\
\hline Small ears & + & 75 & 50 & 78 \\
\hline \multicolumn{5}{|l|}{ Ectodermal signs } \\
\hline Sparse scalp hair & + & 75 & - & 89 \\
\hline Sparse/absent eyebrows & + & 100 & 63 & 100 \\
\hline Sparse/absent eyelashes & + & 100 & 69 & 100 \\
\hline Wrinkled skin/redundant skin & + & 94 & 88 & 89 \\
\hline \multicolumn{5}{|l|}{ Genitalia and anus } \\
\hline Small labia majora & + & 56 & 13 & - \\
\hline Anteriorly located anus & + & 25 & - & NA \\
\hline Growth impairment $\emptyset$ & \pm & 67 & - & NA \\
\hline \multicolumn{5}{|l|}{ Facial morphology } \\
\hline Extension of septum on philtrum & - & - & 50 & 100 \\
\hline Everted upper vermillion & - & - & - & 44 \\
\hline \multicolumn{5}{|l|}{ Ectodermal signs } \\
\hline Hypertrichosis & - & - & 94 & - \\
\hline \multicolumn{5}{|l|}{ Limb anomalies } \\
\hline Syndactyly & - & 44 & 6 & - \\
\hline Camptodactyly & - & 38 & - & - \\
\hline Developmental delay & - & 30 & 25 & 13 \\
\hline
\end{tabular}

AMS, ablepharon macrostomia syndrome; BSS, Barber-Say syndrome; FFDD3, focal facial dermal dysplasia type 3, Setleis syndrome; NA, information not available.

† AMS data from Brancati et al. [13], Marchegiani et al. [19], and De Maria et al. [20].

\# BSS data from Marchegiani et al. [19] and De Maria et al. [20].

§ FFDD3 data from Lee et al. [25] and Ayaz et al. [26]. Only reports of FFDD3 patients with TWIST2 variation are included.

I Growth parameters of our patient were between the 3rd and 10th percentiles.

†† Distichiasis upper lashes in FFDD3 patients, which may resemble entropion, are present in $78 \%$ of reported cases. 
There are several differences that can distinguish FFDD3 from AMS and BSS. The distinct FFDD3 phenotypes are bitemporal scarring, ophthalmological abnormalities such as distichiasis of the upper eyelashes and paucity of lower eyelashes, and ectodermal signs such as sparse eyebrows and/or hair, which are features shared between AMS and BSS [25]. The mode of inheritance for an FFDD3 patient with a TWIST2 variation is autosomal recessive [25]. However, the TWIST2 variation has been identified in only some FFDD3 patients $[25,27,28]$. Another identifiable cause is $1 \mathrm{p} 36.22 \mathrm{p} 36.21$ duplication or triplication, which is an autosomal dominant inheritance [27, 28]. Still, many FFDD3 patients have not had an identifiable genetic cause to date [25].

TWIST2 is located at 2 p37.3 and encodes for a basic helix-loop-helix protein binding to the E-box DNA motifs as a heterodimer with other similar proteins, and is considered as a transcription regulator for mesenchymal stem cell differentiation of chondrogenic and dermal tissues $[2,19,20]$. This variant of TWIST2 results in underdevelopment of eyelids and dysmorphologies of the skin (ectodermal dysplasia) including skin appendages (alopecia, absent or sparse eyebrows, and eyelashes) $[19,20,25]$.

The structural defect of underdevelopment of the eyelids occurs at only the anterior lamella of the eyelids, but not the medial and posterior lamellae resulting in protruding eyelids known as ectropion, with severe cases having the appearance of absence of eyelids. As discussed by De Maria et al., "ablepharon" is a misnomer, but they recommended retaining the term for historical reasons [21]. Severe ectropion leads to an inability to close the eyelids completely and the term "lagophthalmos" can be used to describe the constantly open eyes. The complications of lagophthalmos are eye dryness, corneal abrasions, and superimposed infections.

Our patient was treated with eye lubricants and her eyes were covered by eye shields to prevent corneal abrasion and ulcers. At age 1.5 years, skin grafting on her upper eyelids was performed with good results. The macrostomia existing in our patient was relatively mild compared with previously reported cases, manifesting as only a thin vermillion border at both upper and lower lips.

The other striking clinical characteristics of our patient were multiple skin defects, namely alopecia totalis (absent eyebrows, eyelashes, and hair), and redundant and wrinkled skin. A skin biopsy was not performed, but our best assessment is that the girl might have absent hair follicles and sweat glands. Delayed dentition was also observed, and the girl has been followed for this problem. However, the girl has had no problems with nutritional intake as she has grown well with weight and height gain according to the 3rd-10th percentiles for normal unadjusted growth of Thai girls. Developmental milestones were assessed to be appropriate for age in all domains.

Genital abnormalities have been reported in $50-60 \%$ of patients with AMS, ambiguous genitalia with a small scrotum and micropenis in male patients, and atrophic labia majora or labia minora, or both, in female patients. Our patient had atrophic labia minor and labia majora, and an absent clitoris, which, to our knowledge, has not been reported previously.

\section{Conclusion}

In conclusion, we report a patient with typical clinical characteristics of AMS including severe ectropion, ectodermal dysplasia of alopecia totalis, absent eyebrows and eyelashes, excessive skin folds, macrostomia, and hypoplastic genitalia. Either Sanger sequencing or whole exome sequencing for the missense variant, p.Glu75Lys, of TWIST2 gene confirms the diagnosis of AMS. To our knowledge, this is the first reported case of AMS in a Thai patient, and the first reported case of AMS in Asia.

Author contributions. PK, SJ, and KS conceived the study, SJ supervised the study, and PK investigated the case. KS performed the genetic investigation and all authors contributed to the analysis and interpretation of data. All researchers contributed to drafting and critical revision of the manuscript and approved the final version submitted for publication, and take responsibility for statements made in the published article.

Acknowledgments. We did not receive any specific grants for this research from any funding agency in the public, commercial, or not-for-profit sectors. The authors thank Mr. David Patterson from the International Affairs Office of the Faculty of Medicine, Prince of Songkla University, for English language editing of the manuscript.

Conflict of interest statement. The authors have each completed and submitted an International Committee of Medical Journal Editors Uniform Form for Disclosure of Potential Conflicts of Interest. None of the authors has any potential conflict of interest to disclose in relation to the present article.

Data sharing statement. The data generated or analyzed during the present study are available in the National Center for Biotechnology Information ClinVar repository; [VCV000208077.3], with accession number: SCV001335280.1, and will be shared by the authors upon reasonable request after deidentification of data from any individual patient. Available from: https://www. ncbi.nlm.nih.gov/clinvar/variation/VCV000208077.3 


\section{References}

[1] McCarthy GT, West CM. Ablepharon macrostomia syndrome. Dev Med Child Neurol. 1977; 19:659-72.

[2] O’Neill M. Ablepharon macrostomia syndrome; AMS (\#200110) [Internet]. [cited 2019 Sep 14]. Available from: https://www.omim. org/entry/200110

[3] Hornblass A, Reifler DM. Ablepharon macrostomia syndrome. Am J Ophthalmol. 1985; 99:552-6.

[4] Cesarino EJ, Pinheiro M, Freire-Maia N, Meira-Silva MC. Lid agenesis-macrostomia-psychomotor retardation-forehead hypertrichosis-a new syndrome? Am J Med Genet. 1988; 31:299-304.

[5] Jackson IT, Shaw K, del Pinal Matorras F. A new feature of the ablepharon macrostomia syndrome: zygomatic arch absence. Br J Plast Surg. 1988; 41:410-5.

[6] Markouizos D, Siddiqi U, Siddiqi S, Raziuddin K, Nangia B. Ablepharon macrostomia syndrome: report of a case and clinical delineation. Am J Med Genet. 1990; 47(Suppl):A66.

[7] Price NJ, Pugh RE, Farndon PA, Willshaw HE. Ablepharon macrostomia syndrome. Br J Ophthalmol. 1991; 75:317-9.

[8] Cruz AA, Guimarães FC, Obeid HN, Ferraz VE, Noce TR, Martinez FE. Congenital shortening of the anterior lamella of all eyelids: the so-called ablepharon macrostomia syndrome. Ophthal Plast Reconstr Surg. 1995; 11:284-7.

[9] Pellegrino JE, Schnur RE, Boghosian-Sell L, Strathdee G, Overhauser J, Spinner NB, et al. Ablepharon macrostomia syndrome with associated cutis laxa: possible localization to 18q. Hum Genet. 1996; 97:532-6.

[10] Ferraz VEF, Melo DG, Hansing SE, Cruz AA, Pina-Neto JM. Ablepharon-macrostomia syndrome: first report of familial occurrence. Am J Med Genet. 2000; 283:281-3.

[11] Amor DJ, Savarirayan R. Intermediate form of ablepharonmacrostomia syndrome with CNS abnormalities. Am J Med Genet. 2001; 103:252-4.

[12] Stevens CA, Sargent LA. Ablepharon-macrostomia syndrome. Am J Med Genet. 2002; 107:30-7.

[13] Brancati F, Mingarelli R, Sarkozy A, Dallapiccola B. Ablepharonmacrostomia syndrome in a 46-year-old woman. Am J Med Genet. 2004; 127A:96-8.

[14] Cavalcanti DP, Matejas V, Luquetti D, Mello MF, Zenker M. Fraser and ablepharon macrostomia phenotypes: concurrence in one family and association with mutated FRAS1. Am J Med Genet Part A. 2007; 143A:241-7.
[15] Kallish S, Mcdonald-Mcginn DM, van Haelst MM, Bartlett SP, Katowitz JA, Zackai EH. Ablepharon-macrostomia syndromeextension of the phenotype. Am J Med Genet Part A. 2011; 155:3060-2.

[16] Rohena L, Kuehn D, Marchegiani S, Higginson JD. Evidence for autosomal dominant inheritance of ablepharon-macrostomia syndrome. Am J Med Genet Part A. 2011; 155:850-4.

[17] Larumbe J, Villalta P, Velez I. Clinical variant of ablepharon macrostomia syndrome. Case Rep Dermatol Med. 2011;2011:593045. doi: $10.1155 / 2011 / 593045$

[18] Feinstein E, Traish AS, Aakalu V, Kassem IS. A case report of ablepharon-macrostomia syndrome with amniotic membrane grafting. Case Rep Ophthalmol. 2015; 6:366-72.

[19] Marchegiani S, Davis T, Tessadori F, Van Haaften G, Brancati F, Hoischen A, et al. Recurrent mutations in the basic domain of TWIST2 cause ablepharon macrostomia and Barber-Say syndromes. Am J Hum Genet. 2015; 97:99-110.

[20] De Maria B, Mazzanti L, Roche N, Hennekam RC. Barber-Say syndrome and ablepharon-macrostomia syndrome: an overview. Am J Med Genet Part A. 2016; 170:1989-2001.

[21] Hollanders K, Casteels I, Vandelanotte S, Reyniers R, Segers K, Nevens T, Mombaerts I. Use of the masquerade flap in ablepharonmacrostomia syndrome: a case report. Cornea. 2018; 37:929-32.

[22] Fenton TR, Kim JH. A systematic review and meta-analysis to revise the Fenton growth chart for preterm infants. BMC Pediatr. 2013; 13:59. doi: 10.1186/1471-2431-13-59

[23] O’Neill MF. Barber-Say syndrome; BBRSAY (\# 209885). [Internet]. [cited 2019 Sep 14]. Available from: https://www.omim.org/ entry/209885

[24] O’Neill MF. Focal facial dermal dysplasia 3, Setleis type; FFDD3 (\# 227260). [Internet]. [cited 2019 Sep 14]. Available from: https://www.omim.org/entry/227260

[25] Lee BH, Aggarwal A, Slavotinek A, Edelmann L, Chen B, Desnick RJ. The focal facial dermal dysplasias: phenotypic spectrum and molecular genetic heterogeneity. J Med Genet. 2017; 54:585-90.

[26] Ayaz A, Yalcintepe S, Ozalp Yuregir O, Sahin Y, Ozer A, Eser M, Celik U. The TWIST2 mutation causes Setleis syndrome: a rare clinical case report. Clin Dysmorphol. 2017; 26:128-31.

[27] Weaver DD, Norby AR, Rosenfeld JA, Proud VK, Spangler BE, Ming JE, et al. Chromosome 1p36.22p36.21 duplications/triplication causes Setleis syndrome (focal facial dermal dysplasia type III). Am J Med Genet A. 2015; 167A:1061-70.

[28] Lee BH, Kasparis C, Chen B, Mei H, Edelmann L, Moss C, et al. Setleis syndrome due to inheritance of the $1 \mathrm{p} 36.22 \mathrm{p} 36.21$ duplication: evidence for lack of penetrance. J Hum Genet. 2015; 60:717-22. 